\title{
25 Research Soure \\ Expression and function of an HAC1-regulated multi-copy xylanase gene in Saccharomyces cerevisiae
}

\section{Sitong Zhang ( $D$ 18943132269@163.com )}

key laboratory of straw biology and utilization $\otimes T$ The ministry of education https://orcid.org/0000-00023629-9708

\section{Changjie Bao}

key laboratory of straw biology and utilization $₫$ The ministry of education

Jiping Li

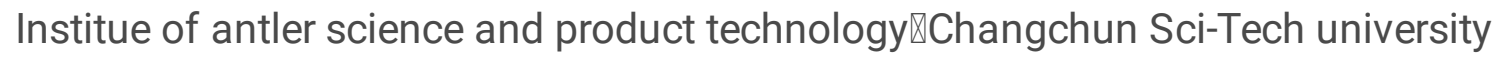

\section{Huan Chen}

college of life science, Jilin agricultural university

\section{Yang Sun}

Key laboratory of straw biology and utilization $\bigotimes$ The ministry of education

\section{Gang Wang}

Northeast Normal University Institute of Polyoxometalate Chemistry

Guang Chen

Key laboratory of straw biology and utilization $\otimes T$ The ministry of education

\section{Research}

Keywords: HAC1, multi-copy, Saccharomyces cerevisiae, xylanase, protein folding in the endoplasmic reticulum

Posted Date: February 24th, 2020

DOl: https://doi.org/10.21203/rs.2.24254/v1

License: (c) (i) This work is licensed under a Creative Commons Attribution 4.0 International License. Read Full License 


\section{Abstract}

To investigate the effects of transcription factor $\mathrm{HAC1}$, which is involved in the unfolded protein response pathway, on the expression of xynB in Saccharomyces cerevisiae, we used overlap extension polymerase chain reaction (PCR), rDNA integration, and droplet digital PCR technology to generate a $S$ . cerevisiae strain (S8) containing eight copies of the xylanase gene, allowing high-yield secretory expression of xylanase. HAC1 was then overexpressed in the S8 strain, and the GeXP system was used to study the effects of HAC1 overexpression on the expression of genes associated with protein folding in the endoplasmic reticulum (ER). Results confirmed the constitutive secretory expression of the multiple copies of the xylanase gene in $S$. cerevisiae following rDNA-based integration of the expression cassette. Specifically, recombinant $S$. cerevisiae strain S8, containing eight copies of the xylanase gene, showed maximum xylanase expression, with a yield of $325 \mathrm{U} / \mathrm{mL}$. However, overexpression of HAC1 further improved xylanase production by strain $\mathrm{S} 8$, resulting in a yield of $381 \mathrm{U} / \mathrm{mL}$. These results confirmed that overexpression of HAC1 improves the expression of genes associated with protein folding in the ER, enhancing the protein folding and assembly functions of the ER and increasing xylanase expression.

\section{Introduction}

Xylanase, a microbial hydrolase used to degrade xylan into xylooligosaccharide and xylose, plays a major role in the energy industry but is also widely applied in fields ranging from livestock feed and human food

production to papermaking ${ }^{[1,2]}$. The main factor limiting the production and application of xylanase is the lack of high-yield bacterial and fungal strains that can be adapted to large-scale production. Therefore, it is imperative to research and develop new high-yield xylanase-producing strains ${ }^{[3]}$.

Approved by the Food and Drug Administration of the United States as a safe species, Saccharomyces cerevisiae is an ideal host for the expression of enzymes used in food and feed production ${ }^{[4]}$. With its clear biological and genetic background, S. cerevisiae boasts the advantageous features of prokaryotes, including fast growth and reproduction and simple genetic manipulation procedures, as well as posttranslational modification of heterologous proteins that is common to eukaryotes. As such, S. cerevisiae has been widely studied and used for the expression of heterologous genes ${ }^{[5,6]}$. Ribosomal DNA (rDNA), coding for ribosomal RNA, consists of a tandem repeat of a unit containing both transcribed and untranscribed regions. S. cerevisiae chromosome 12 contains approximately 100-140 repeating rDNA units; thus, if the rDNA sequence is used as an integration site, 100-140 copies of a target gene should theoretically be obtained ${ }^{[7,8]}$. Dosage effects mean that highly efficient gene expression is achieved in $\mathrm{S}$. cerevisiae following rDNA-mediated integration of heterologous genes.

The unfolded protein response (UPR) signaling pathway, an endoplasmic reticulum (ER) stress protection mechanism, acts as a quality control mechanism in the synthesis of secreted or membrane-localized proteins, ensuring proper protein folding or degradation ${ }^{[10]}$. Multiple proteins are involved in the signaling pathway. As a transcription factor, HAC1 is considered a key regulatory factor of the UPR pathway. CPR5 is a cyclophilin, the main functions of which are to affect peptidyl-prolyl cis-trans isomerase, participate 
in post-translational modification of proteins, and maintain the homeostasis of intracellular metal ions. CNE1, a calcium-binding protein, acts as a molecular chaperone in the ER and participates in protein folding and glycosylation modification. PDI oxidase ERO1 controls the folding of oxidized proteins in the ER, while KAR2 is a Bip-binding protein that transports proteins to the ER with the help of an ATPase and also acts as a molecular chaperone, assisting with protein folding. Protein disulfide-isomerase PDI1 acts as a multifunctional molecular chaperone in the ER and plays a major role in the formation of disulfide bonds. Finally, SEC53, a phosphomannomutase, is involved in the synthesis of GDP-mannose and mannose 6-phosphate, which are required for the folding and glycosylation of secretory proteins in the ER lumen. The genes coding for each of these proteins are likely to be affected by HAC1-mediated activation of the UPR, resulting in both short- and long-term physiological effects ${ }^{[9,10]}$.

Droplet digital polymerase chain reaction (ddPCR) is a recently developed absolute gene quantification method that works by amplifying a single molecule by means of extreme dilution, and determines the original concentration of the sample by applying end-point PCR and Poisson distribution. The method displays high levels of accuracy and reproducibility, ensuring absolute quantification ${ }^{[11,12]}$.

The GeXP genetic analysis system, developed by Beckman Coulter, is a platform for quantitative multigene expression analysis, and represents a new platform for quantitative analysis of gene expression profiling. The system combines capillary electrophoresis-based separation with highly sensitive laserinduced fluorescence technology to achieve higher sensitivity and speed for quantitative analysis of gene expression. Using mRNA as the template, multiple PCR reactions initiated by fluorescently labeled universal primers and specific chimeric primers in the same reaction system allow quantitative analysis of up to 25 reverse-transcriptase PCR products. The GeXP systems is an advance over existing chipbased and quantitative PCR technologies, allowing the monitoring of dozens to hundreds of genes and the processing of thousands of samples ${ }^{[13]}$.

In the current study, by ligating constitutive promoter PGK, the a-factor signal peptide, the xynB mature peptide sequence, and the CYC1 terminator, we obtained an expression cassette termed PaXC. An rDNA integration method was then used to construct multi-copy xylanase $S$. cerevisiae strains to study the relationship between copy number and xylanase expression. By overexpressing HAC1 in the strains, the multi-copy xylanase expression was optimized. Furthermore, GeXP technology was applied to study the impact of overexpressing HAC1 gene on the expression of the genes associated with protein folding in the endoplasmic reticulum, providing a theoretical basis for reconstructing and modifying xylanase production strains.

\section{Materials And Methods}

\subsection{Strains, plasmids, media, and culture conditions}

The strains and plasmids used in this study are shown in Table 1. Escherichia coli DH5a was used as the host for gene cloning assays. S. cerevisiae INVSc1 (Invitrogen, Carlsbad, CA, USA) was selected for use in 
this study because it shows high level expression of heterologous proteins. Strain INVSc1 was used as the host for xynB expression and to amplify the PKG promoter sequence (850 bp, GenBank accession number: AH001380), the rDNA sequence (2,300 bp, GenBank accession number: BK006945.2), and HAC1 (717 bp, GenBank accession number: NM_001179935). Aspergillus niger strain CICC2462 was used as template to amplify xynB (984 bp, GenBank accession number: FJ986225.1), while plasmids pPic9k and pSH65 were used as templates to amplify the a-factor secretion signal sequence (255 bp, GenBank accession number: KM032189) and CYC1 (254 bp, GenBank accession number: AF298780.1), respectively. S. cerevisiae INVSc1-pYES2-xynB, a single-copy xylanase S. cerevisiae expression strain, was used to express xylanase under galactose induction ${ }^{[14]}$. 
Table 1

Strains and plasmids used in this study

\begin{tabular}{lll} 
Strains & Characteristics & Sources \\
\hline E. coli DH5a & Host of gene cloning & Takara, Japan \\
\hline Aspergillus Niger ClCC2462 strain & Used to clone xynB gene & $\begin{array}{l}\text { China Center of } \\
\text { Industrial Culture } \\
\text { Collection }\end{array}$
\end{tabular}

S. Cerevisiae INVSc1 (Hereinafter

referred to as SO)

S.Cerevisiae INVSc1-pYES2-xynB

(Hereinafter referred to as S1)

$\mathrm{PaXC}$ (Hereinafter referred to as $\mathrm{SN}$ )

S. Cerevisiae INVSc1-HAC1 (Hereinafter referred to as $\mathrm{SO}-\mathrm{H}$ )

S. Cerevisiae INVSc1-pYES2-PaXC-

$\mathrm{HAC1}$ (Hereinafter referred to as S1-H)

S. Cerevisiae INVSc1-pYES2-N $\times$ PaXCHAC1 (Hereinafter referred to as $\mathrm{SN}-\mathrm{H}$ )

\section{Plasmid}

pYES2

pYES6

pPIC9K $\begin{array}{ll}\text { Expression host of MATa, his3, leu2, } & \text { Invitrogen, } \\ \text { trp, ura3 } & \text { America }\end{array}$

Lan et al.(2017)

Galactose induced xylanase

Saccharomyces cerevisiae

expression

Constitutive single-copy expression This study

of xylanase gene Saccharomyces

cerevisiae

Constitutive multi-copy expression

of xylanase gene Saccharomyces

cerevisiae

HAC1 gene overexpression of wildtype Saccharomyces cerevisiae

HAC1 gene overexpression of singlecopy xylanase gene Saccharomyces cerevisiae

HAC1 gene overexpression of multicopy xylanase gene Saccharomyces cerevisiae

Characteristics

Expression host of ura3

Saccharomyces cerevisiae

Host of Blasticidin resistance and

the expression Saccharomyces cerevisiae ura3

Applied to amplify signal peptide afactor sequence
This study

This study

This study

This study

Source

Invitrogen, America

Invitrogen, America

China Center for Type Culture Collection

E. coli DH5a was cultured in Luria-Bertani medium at $37^{\circ} \mathrm{C}$. S. cerevisiae INVSc1 cultures and fermentation were performed in YPD medium containing $20 \mathrm{~g} / \mathrm{L}$ peptone, $10 \mathrm{~g} / \mathrm{L}$ yeast extract, and $10 \mathrm{~g} / \mathrm{L}$ glucose, and were incubated at $30^{\circ} \mathrm{C}$. Synthetic complete-ura (SC-U) auxotrophic medium without uracil (Clontech, Mountainview, CA, USA) was used for the selection of S. cerevisiae INVSc1pYES2-PaXC recombinants. Xylan-Congo red medium ( $20 \mathrm{~g} / \mathrm{L}$ peptone, $10 \mathrm{~g} / \mathrm{L}$ yeast extract, $10 \mathrm{~g} / \mathrm{L}$ xylan (Sigma Aldrich, St Louis, MO, USA), $18 \mathrm{~g} / \mathrm{L}$ agar, and $1 \%(\mathrm{w} / \mathrm{v})$ Congo red) was used as a xylanase vitality culture medium, with cultures incubated at $30^{\circ} \mathrm{C}$. 


\begin{tabular}{|c|c|c|}
\hline Strains & Characteristics & Sources \\
\hline pMD19-T & Host of gene cloning & Takara, Japan \\
\hline pSH65 & Used to amplify terminator $\mathrm{CYC} 1$ & $\begin{array}{l}\text { China Center for } \\
\text { Type Culture } \\
\text { Collection }\end{array}$ \\
\hline pYES2-PaXC & $\begin{array}{l}\text { Expression host of constitutive } \\
\text { single-copy xylanase }\end{array}$ & This study \\
\hline pYES2-PaXC-rDNA & $\begin{array}{l}\text { Expression host of constitutive } \\
\text { multi-copy xylanase }\end{array}$ & This study \\
\hline pYES6-PGK-HAC1 & HAC1 gene overexpression host & This study \\
\hline \multicolumn{3}{|c|}{ 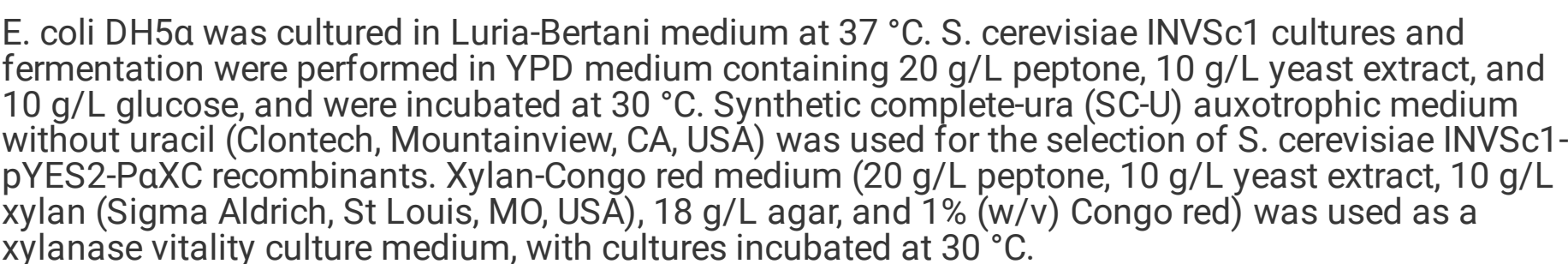 } \\
\hline
\end{tabular}

\subsection{Construction of the PaXC expression cassette by overlap extension PCR}

Following activation, A. niger strain $\mathrm{ClCC} 2462$ was inoculated into liquid fermentation medium and cultivated at $30^{\circ} \mathrm{C}$ and $150 \mathrm{rpm}$ for $72 \mathrm{~h}$. Cells were collected by centrifugation and RNA was extracted from the cell pellets using an AXYGEN Total RNA Extraction Kit (Fisher Scientific, Waltham, MA, USA). A PrimeScript One Step RT-PCR Kit (Takara Bio, Kusatsu, Japan) was then used to generate cDNA, which was used as template to amplify xynB.

S. cerevisiae INVSc1 genomic DNA was used as a template to amplify the phosphoglycerate kinase (PGK) promoter sequence, while plasmids pPIC9K and pSH65 were used as templates to amplify the afactor secretion signal sequence and the $\mathrm{CYC} 1$ terminator sequence, respectively. Overlap extension PCR was used to ligate the four sequences, generating a PGK-a-factor-xynB-CYC1 expression cassette designated PaXC. EcoRI and Xbal recognition sites were introduced upstream of PGK and downstream of CYC1, respectively. Primers used for all amplifications are shown in Table 2. 
Table 2

Primers used in this study

\begin{tabular}{|c|c|c|}
\hline Prime & Sequence $\left(5^{\prime}-3^{\prime}\right)$ & Annotation \\
\hline $\begin{array}{l}\text { xynB- } \\
\text { F }\end{array}$ & ATGGTTCAGATCAAGGTAGCTG & $\begin{array}{l}\text { Used to } \\
\text { amplify xynB } \\
\text { gene }\end{array}$ \\
\hline $\begin{array}{l}\text { xynB- } \\
\text { R }\end{array}$ & CTAGAGAGCATTTGCGATAGC & $\begin{array}{l}\text { Used to } \\
\text { amplify xynB } \\
\text { gene }\end{array}$ \\
\hline PGK-F & CCGGAATTCAGCTTTCTAACTGATCTATCCAAAAC & $\begin{array}{l}\text { EcoRI was } \\
\text { used to } \\
\text { amplify PGK } \\
\text { sequence }\end{array}$ \\
\hline PGK-R & GCTGCCTTGATCTGAACCATTGTTTTATATTTGTTGTAAAAAGTAGA & $\begin{array}{l}\text { Used to } \\
\text { amplify PGK } \\
\text { sequence }\end{array}$ \\
\hline $\begin{array}{l}\text { a- } \\
\text { factor- } \\
\text { F }\end{array}$ & TCTACTTTTTACAACAAATATAAAACAATGAGATTTCCTTCAATTTTTACTGC & $\begin{array}{l}\text { Used to } \\
\text { amplify a- } \\
\text { factor signal } \\
\text { sequence }\end{array}$ \\
\hline $\begin{array}{l}\text { a- } \\
\text { factor- } \\
\text { R }\end{array}$ & TGTCGATGCTCACTGAAGCCTGTCTTTTCTCGAGAGATACCCCTT & $\begin{array}{l}\text { Used to } \\
\text { amplify a- } \\
\text { factor } \\
\text { sequence }\end{array}$ \\
\hline $\begin{array}{l}\text { xynB- } \\
\text { F1 }\end{array}$ & AAGGGGTATCTCTCGAGAAAAGACAGGCTTCAGTGAGCATCGACA & $\begin{array}{l}\text { Used to } \\
\text { amplify } \\
\text { mature } \\
\text { peptide xynB } \\
\text { gene }\end{array}$ \\
\hline $\begin{array}{l}\text { xynB- } \\
\text { R1 }\end{array}$ & GCGTGACATAACTAATTACATGACCTAGAGAGCATTTGCGATAGCAGTGT & $\begin{array}{l}\text { Used to } \\
\text { amplify } \\
\text { mature } \\
\text { peptide xynB } \\
\text { gene }\end{array}$ \\
\hline $\begin{array}{l}\text { CYC1- } \\
\text { F }\end{array}$ & ACACTGCTATCGCAAATGCTCTCTAGGTCATGTAATTAGTTATGTCACGC & $\begin{array}{l}\text { Used to } \\
\text { amplify CYC1 } \\
\text { sequence }\end{array}$ \\
\hline $\begin{array}{l}\text { CYC1- } \\
\text { R }\end{array}$ & TGCTCTAGACGGCCGCAAATTAAAGCCTT & $\begin{array}{l}\text { Xbal was } \\
\text { used to } \\
\text { amplify CYC1 } \\
\text { sequence }\end{array}$ \\
\hline
\end{tabular}


The PaXC expression cassette was ligated into pMD19-T and transformed into electrocompetent E. coli DH5a before being extracted and confirmed by sequencing. The extracted pMD19-T-PaXC plasmid and vector PYES2 were then digested with EcoRI and Xbal, respectively, visualized by agarose gel electrophoresis, and the target fragment recovered from the agarose gel. The gel-purified fragment was then ligated into the linearized pYES2 vector using T4 ligase, generating plasmid pYES2-PaXC. The recombinant plasmid was then transformed into electrocompetent E. coli DH5a.

S. cerevisiae INVSc1 genomic DNA was used as template to amplify the 2,300-bp core sequence of the rDNA unit using primers rDNA-F (ACGTACGTACAACGAACGAGACCTTAACCT) and rDNA-R (ACGTACGTACGGAACCTCTAATCATTCGCT), both of which introduced SnaBI restriction enzyme recognition sites into the resulting DNA fragment. pYES2-PaXC and pMD19-T-rDNA(constructed by TA clone) were then digested with SnaBI and the target fragments were recovered by gel purification. T4 ligase was used to ligate the target fragments, generating recombinant expression vector PYES2-PaXCrDNA. pYES2-PaXC-rDNA was then linearized at the rDNA loci using Sphl, and the LiAc/ssDNA method ${ }^{[15 \text {, }}$

${ }^{16]}$ was used to transform the linearized vector into electrocompetent S. cerevisiae INVSc1. Recombinants were selected by culture on SC-U medium for $3-5$ days.

\subsection{Identification of transformant copy number using droplet digital PCR (ddPCR)}

Transformants were inoculated into YPD medium and cells were collected after $48 \mathrm{~h}$ of cultivation. A yeast genome extraction kit (Omega Bio-tek, Norcross, GA, USA) was used to extract genomic DNA for use as template for ddPCR. The QX200 ddPCR System (Bio-Rad Laboratories, Hercules, CA, USA) was then used to identify xynB gene copy number using the following primers and probes: ATC1: F1 (5囚ATC1TATCCCCTGCATCCCTATCA-3区), R1 (5囚-CAGGCTTCGTTGCAGATACA-3囚), and probe (5囚-HEX-

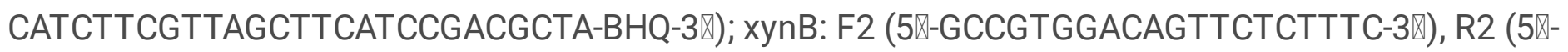
TCATGACCCCGATGAGTGTA-3囚), and probe (5囚-FAM-CCTGGTCAACTTTGCCCAGTCTAACAA-BHQ-3囚). Reference gene ATC1 was fluorescently labelled with HEX, while target gene xynB was labelled with FAM.

ddPCR reactions were carried out in $20-\mu \mathrm{L}$ volumes containing $10 \mu \mathrm{L}$ of $2 \times$ ddPCR Master Mix, $1 \mu \mathrm{L}$ each of $10 \mu \mathrm{mol} / \mathrm{L}$ forward and reverse primers, $0.5 \mu \mathrm{L}$ of probe, and $2 \mu \mathrm{L}$ of DNA template. To generate droplets, specialized droplet generator cartridges and gaskets and a droplet generator were used. For each reaction, $40 \mu \mathrm{L}$ of reaction mixture and $70 \mu \mathrm{L}$ of droplet generation oil were added to droplet generator cartridges, covered with specialized gaskets, and placed into the droplet generator. A two-step ddPCR amplification protocol was used, including a pre-denaturation step at $94^{\circ} \mathrm{C}$ for $10 \mathrm{~min}$, followed by 45 cycles of $94^{\circ} \mathrm{C}$ for $15 \mathrm{~s}, 60^{\circ} \mathrm{C}$ for $1 \mathrm{~min}$, and $98^{\circ} \mathrm{C}$ for $10 \mathrm{~min}$. Each template was assayed in triplicate. Following amplification, 96-well plates were transferred to the reader and analyzed using QuantaSoft to obtain the absolute quantification ${ }^{[17]}$.

\subsection{Fermentation of transformants to obtain xylanase}


Transformants carrying different numbers of copies of xynB were separately inoculated into galactose medium in a fermenter and incubated at $30^{\circ} \mathrm{C}$ for $72 \mathrm{~h}$ with an agitation speed of $150 \mathrm{rpm}$. Xylanase

activity in the resulting cultures was determined using the DNS method as described previously ${ }^{[18]}$. The standard curve of the xylose regression equation was as follows: $y=0.1275 x-0.07$, with $R^{2}=0.9935$.

\subsection{Overexpression of HAC1 in the recombinant xylanase- producing S. cerevisiae strains}

S. cerevisiae INVSc1 genomic DNA was used as the template for amplification of the PGK promoter using primers PGK-F1 (CCCAAGCTTCTGCCCCAGGTTCCGTTATT) and PGK-R1

(CGCGGATCCACCGAAGGCATCGTTGATGT). The resulting amplicon was ligated into pYES6 at the HindIII and BamHI sites, generating recombinant plasmid pYES6-PGK.

S. cerevisiae strain INVSc1 was inoculated into YPD broth and incubated in a shaking incubator overnight at $30^{\circ} \mathrm{C}$. The concentration of DDT in the medium was then adjusted with sterilized DDT to a final concentration of $5 \mathrm{mM}$, and the culture was returned to the incubator for $6 \mathrm{~h}$ at $30^{\circ} \mathrm{C}$. With DDT induction, a large number of unfolded proteins are accumulated by yeast cells, which induces the UPR, resulting in HAC1 transcription. RNA was extracted from the DDT-induced cells and reverse-transcribed into CDNA using a one step RT-PCR kit. The resulting CDNA was used as template for amplification of HAC1 using primers HAC1-F (CCCGGATCCATGGAAATGACTGATTTTG) and HAC1-R

(CCCTCTAGATCATGAAGTGATGAAGAAATC).

The HAC1 amplicon was then ligated into pYES6-PGK via double-enzyme digestion, and the resulting recombinant plasmid, named pYES6-PGK-HAC1, was confirmed by sequencing. pYES6-PGK-HAC1 was then linearized and transformed into various $S$. cerevisiae recombinant strains carrying different numbers of copies of xynB. Blasticidin resistance was used as a selective marker for the resulting transformants.

\subsection{Detection of expression levels of genes associated with protein folding in the ER using the GeXP system}

Qualitative and quantitative analysis of multi-gene expression can be achieved using GeXP technology.

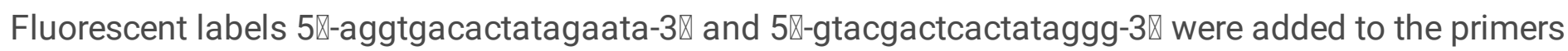
used to amplify the target genes, meaning that the resulting fragments were 37-bp larger than the original amplicon size. The GeXP detection process includes five steps: 1) design multiplex primer sets using NCBI Primer-BLAST; 2) perform reverse transcription reaction; 3) perform PCR reaction; 4) run PCR products on the GeXP system; and 5) carry out data analysis using the GeXP fragment analysis module, GeXP data tool, and GeXP quantitative tool.

S. cerevisiae recombinant strains S0 (wild-type strain INVSc1), S0-H (wild-type strain expressing HAC1), S1 (single-copy xynB strain), S1-H (single-copy xynB strain expressing HAC1), S8 (strain carrying eight copies of $x y n B$ ), S8-H (strain carrying eight copies of $x y n B$ and expressing HAC1; showed the highest 
xylanase production), S22 (strain carrying 22 copies of xynB; the highest copy-number strain), and S22-H (strain carrying 22 copies of xynB and expressing HAC1) were individually inoculated into YPD medium and incubated at $30^{\circ} \mathrm{C}$. Samples were collected at $24 \mathrm{~h}, 48 \mathrm{~h}$, and $72 \mathrm{~h}$ post-inoculation and subjected to RNA extraction. RNA samples were then reverse-transcribed into CDNA and used as template for PCR assays for GeXP-based analysis of the expression of CPR5, CNE1, ER01, KAR2, HAC1, PDI1, and SEC53, all of which are associated with protein folding in the ER. The expression of $x y n B$ at each of the time points was also assessed by GeXP. The primers and the sizes of the resulting fragments are shown in Table 3.

Table 3

Primers and fragment sizes for GeXP assays

\begin{tabular}{|c|c|c|c|}
\hline Prime & Sequence $\left(5^{\prime}-3^{\prime}\right)$ & Fragment length & Testing length \\
\hline CPR5-F & aggtgacactatagaatacaccacaccccaaaccgttg & \multirow[t]{2}{*}{303} & \multirow[t]{2}{*}{340} \\
\hline CPR5-R & gtacgactcactatagggaacgtgcttaccgtccaacca & & \\
\hline CEN1-F & gtacgactcactatagggatgcagatttgcagaaatacaaga & \multirow[t]{2}{*}{306} & \multirow[t]{2}{*}{343} \\
\hline CEN1-R & gtacgactcactatagggagcatactaaggcacacttatgcaa & & \\
\hline ER01-F & aggtgacactatagaatatctcaccacaccccaaaccg & \multirow[t]{2}{*}{313} & \multirow[t]{2}{*}{350} \\
\hline ER01-R & gtacgactcactatagggaccaaagacaacgtgcttaccgt & & \\
\hline HAC1-F2 & aggtgacactatagaataaagacgcgttgacttgcagc & \multirow[t]{2}{*}{323} & \multirow[t]{2}{*}{360} \\
\hline HAC1-R2 & gtacgactcactatagggacagagtgggtctgccaacgg & & \\
\hline KAR2-F & aggtgacactatagaataggtaagaaggcctccaagggt & \multirow[t]{2}{*}{335} & \multirow[t]{2}{*}{372} \\
\hline KAR2-R & gtacgactcactatagggacttggtgctggtggaatgcc & & \\
\hline PDI1-F & aggtgacactatagaataaccttggcccagatcgactg & \multirow[t]{2}{*}{345} & \multirow[t]{2}{*}{382} \\
\hline PDI1-R & gtacgactcactatagggaatcgtctgcgttttcagcgg & & \\
\hline SEC53-F & aggtgacactatagaatagctgcattggtttgtcggt & \multirow[t]{2}{*}{359} & \multirow[t]{2}{*}{396} \\
\hline SEC53-R & gtacgactcactatagggactcaccgagccagttgatga & & \\
\hline xynB-F4 & aggtgacactatagaatagtcatcggcgaggactacgt & \multirow[t]{2}{*}{370} & \multirow[t]{2}{*}{407} \\
\hline xynB-R4 & gtacgactcactatagggacgactccccacacggtgata & & \\
\hline
\end{tabular}

\section{Results}

\subsection{Construction of the PaXC expression cassette}


Following amplification of the fragments needed to construct the expression vector (PGK, a-factor signal sequence, $x y n B$, and $C Y C 1$ ), the optimal conditions for overlap extension PCR were determined. The resulting full-length expression cassette, named PaXC, was 2,365 bp in length, and the downstream region of gene contained loci where two sequences could be ligated. Gel electrophoresis-based analysis of the separate amplicons is shown in Fig. S1.

\subsection{Construction of multi-copy xynB S. cerevisiae INVSc1- pYES2-PaXC-rDNA strains}

The pYES2-PaXC vector was confirmed by sequencing by Genewiz (Suzhou, China) (Fig. S2). Following digestion with SnaBI, pYES2-PaXC was dephosphorylated and ligated with SnaBI-treated rDNA, generating pYES2-PaXC-rDNA (Fig. S3). Sphl-treated pYES2-PaXC-rDNA, linearized at the rDNA loci, was transformed into $S$. cerevisiae INVSc1 using the optimized LiAC/ssDNA chemical method ${ }^{[19]}$. Transformants were selected on SC-U auxotrophic medium followed by Congo red medium with xylan as the sole carbon source (Fig. S4). The xylanase-producing capacity of the transformants was preliminarily assessed based on the size of the hydrolysis circle surrounding each colony. Differences in the diameters of the hydrolysis circles of the transformants indicated that the recombinant strains contained different numbers of copies of xynB.

\subsection{Evaluation of the effects of PGK and the a-factor signal peptide on xylanase expression}

To achieve constitutive extracellular expression of xylanase, S. cerevisiae strain INVSc1-pYES2-xynB was generated and inoculated in YPD medium containing galactose instead of glucose. The selected $\mathrm{S}$. cerevisiae INVSc1-pYES2-PaXC strains were also cultivated for $72 \mathrm{~h}$, with samples collected every $4 \mathrm{~h}$ after the first $24 \mathrm{~h}$. The xylanase activity of the culture supernatants from each strain was then examined (Fig. 1). Maximum xylanase activity was observed for S. cerevisiae strain INVSc1-pYES2-PaXC at $72 \mathrm{~h}$ post-inoculation; however, strain INVSc1-pYES2-PaXC showed higher levels of xylanase activity than strain INVSc1-pYES2-xynB throughout the experimental period, indicating that the PGK promoter and the a-factor signal peptide contributed to xylanase production. We hypothesized that the PGK promoter ensured the constitutive expression of $x y n B$, and that the $a$-factor signal peptide effectively enabled the extracellular secretion of synthesized xylanase.

\subsection{Relationship between xynB copy number and xylanase activity as determined by ddPCR}

DNA was extracted from selected S. cerevisiae INVSc1-pYES2-PaXC-rDNA transformants, and ACT1 was used as a reference to determine xynB copy number in each strain (Fig. S5 and Table 4). The detected droplet range was between 10,987 and 14,683 . Because both values were $>10,000$, corresponding to Poisson distribution, it is likely that the results were credible. The identified copy numbers were $2.11,2.98$, $5.04,6.95,8.07,9.0212 .09,15.18,17.92,19.98$, and 22.00 . 
Table 4

Analysis of xynB copy numbers in S. cerevisiae INVSc1-pYES2-PaXCrDNA transformants by ddPCR

\begin{tabular}{|llll|}
\hline Sample & Droplets & Concentration(copies $\cdot \mathrm{LL}^{-1}$ ) & Copy number \\
\hline 1 & 13682 & 1578 & 15.18 \\
\hline 2 & 12109 & 1098 & 12.09 \\
\hline 3 & 12784 & 780 & 5.04 \\
\hline 4 & 11099 & 975 & 9.02 \\
\hline 5 & 14683 & 3289 & 22.00 \\
\hline 6 & 11502 & 2698 & 6.95 \\
\hline 7 & 12846 & 3700 & 2.98 \\
\hline 8 & 12198 & 298 & 2.11 \\
\hline 9 & 13108 & 892 & 19.98 \\
\hline 9 & 10987 & 657 & 8.07 \\
\hline 10 & 14542 & 1884 & 17.92 \\
\hline
\end{tabular}

The ddPCR analysis suggested that 12 xylanase-expressing recombinant strains with $1,2,3,5,7,8,9,12$, $15,18,20$, and 22 copies of $x y n B$, respectively, were successfully generated in this study. All of the strains expressed and secreted xylanase during cultivation in TPD medium. We then compared the xylanase activity of fermentation broth from each of the strains to determine the relationship between enzyme activity and gene copy number (Fig. 2). Results showed that xylanase activity increased with increasing xynB copy number. Xylanase activity increased almost exponentially up to three copies of xynB; however, activity began to decrease with gene copy numbers greater than eight. Therefore, maximum xylanase activity was obtained at eight copies of $x y n B$, reaching a final yield of $325 \mathrm{U} / \mathrm{mL}, 4.35$-fold higher than the yield of the one-copy transformant. At 18 gene copies, xylanase activity decreased to $181 \mathrm{U} / \mathrm{mL}$, only $49 \%$ of the yield of the eight-copy strain. Similarly, at 22 copies, the xylanase activity was only $44 \%$ of that of the eight-copy strain, but was higher than that of the one-copy strain. These results demonstrated that increases in gene copy number did not necessarily lead to increases in protein expression.

\subsection{Effects of overexpression of HAC1 on the expression of xylanase in recombinant $\mathrm{S}$. cerevisiae strains}

Because HAC1 contains a 250-bp intron, it is not expressed in normal S. cerevisiae cells. However, when improperly folded proteins accumulate in the ER, HAC1 is spliced, the intron is removed, and active HAC1 protein is expressed ${ }^{[19]}$. Therefore, in the current study, improper protein folding was induced in wild-type 
S. cerevisiae using DTT, a protein folding inhibitor, allowing amplification of activated HAC1. By ligating the HAC1 amplicon and constitutive expression promoter PGK into pYES6, we generated expression vector pYES6-PGK-HAC1 (Fig. S6). pYES6-PGK-HAC1 was transformed into wild-type S. cerevisiae strain S0 and recombinant strains S1, S8, S9, and S22 (Fig. S7), generating xylanase- and HAC1-expressing strains named $\mathrm{S} 0-\mathrm{H}, \mathrm{S} 1-\mathrm{H}, \mathrm{S} 8-\mathrm{H}, \mathrm{S} 9-\mathrm{H}$, and $\mathrm{S} 22-\mathrm{H}$, respectively.

Following culture in YPD medium, we next compared the xylanase activity of the supernatants of strains S1-H, S8-H, S9-H, and S22-H with that of strains S1, S8, S9, and S22 (Fig. 3). Results showed that the xylanase activity of recombinant strain $\mathrm{S} 8 \mathrm{H}$ was $17.2 \%$ higher than that of $\mathrm{S} 8$, reaching a final yield of $381 \mathrm{U} / \mathrm{mL}$. In addition, the xylanase activities of strains S9-H and S22-H were $14.7 \%$ and $11.7 \%$ higher than those of strains S9 and S22, respectively, while there was no observable difference between strains $\mathrm{S} 1-\mathrm{H}$ and $\mathrm{S} 1$. The results suggested that heterologous protein expression in the single-copy xynB strain did not cause ER stress, and that with nine copies of xynB, overexpression of HAC1 did not increase enzyme activity over that of the eight-copy strain. These results suggested that eight copies of $x y n B$ is optimal for peak xylanase expression in the S. cerevisiae expression system.

\subsection{Effects of HAC1 overexpression on the expression of genes associated with protein folding in the ER}

\subsubsection{Specificity of primers used to amplify genes associated with protein folding in the ER}

In the GeXP electrophoretogram, the abscissa was used to represent the sequence size, while the size of the test fragment was determined based on the marker sizes. cDNA from the 24-h S8-H culture was used as the template. Primers targeting CPR5, CNE1, ER01, KAR2, HAC1, PDI1, SEC53, and xynB were mixed in equal proportions to prepare the reaction mix, and GeXP-based analysis was conducted to investigate primer specificity (Fig. 4). In the figure, the red line represents the marker, with peaks (indicating the bands) at 340-400 bp. The results showed good amplification of all eight genes, which could be used for subsequent experiments, and confirmed that the primers, general labels, and fluorescent labels worked effectively.

\subsubsection{Effects of overexpression of HAC1 on genes associated with protein folding in the ER in strains $\mathrm{SO}$ and S8}

To investigate the effects of overexpression of HAC1 on the expression of protein folding-associated genes in wild-type strain S0, the expression of protein folding-associated genes in strains $\mathrm{SO}$ and $\mathrm{SO}-\mathrm{H}$ at $24 \mathrm{~h}, 48 \mathrm{~h}$, and $72 \mathrm{~h}$ post-inoculation were examined using the GeXP system. The results for the two strains over the same time period were compared and analyzed using GeXP data analysis (Fig. S8A-C). 
Because xynB was not present in either $\mathrm{SO}$ or $\mathrm{S} 0-\mathrm{H}$, xylanase protein was not expressed and the band corresponding to the 407-bp xynB gene was absent.

As shown in Fig. S8A, the expression levels of all protein folding-associated genes apart from KAR2 and $\mathrm{HAC} 1$ were higher in strain $\mathrm{S} 0$ than in $\mathrm{SO}-\mathrm{H}$ at $24 \mathrm{~h}$ post-inoculation. This may be because at $24 \mathrm{~h}$, strains were growing and needed a good supply of proteins, with the ER capable of meeting the requirements of protein folding and assembly. Therefore, the UPR mechanism was not needed. It is also possible that the expression of HAC1, introduced on the vector, lagged behind that of native gene expression, meaning that HAC1 was not fully expressed. At $48 \mathrm{~h}$ post-inoculation, the expression of seven protein foldingassociated genes in S0-H was higher than that in S0 (Fig. S8B and C), indicating the accumulation of secondary metabolites and the overexpression of HAC1, resulting in increased expression of other protein-folding associated genes in $\mathrm{SO}-\mathrm{H}$. Preliminary studies showed that overexpression of HAC1 significantly elevated the expression of xylanase in strain S8. Further investigation of the effects of overexpression of $\mathrm{HAC} 1$ on the expression of ER protein folding-associated genes in strain $\mathrm{S} 8$ confirmed that overexpression of $\mathrm{HAC} 1$ increased the expression of heterologous protein. The expression levels of the various genes in strains S8 and S8-H were then examined at $24 \mathrm{~h}, 48 \mathrm{~h}$, and $72 \mathrm{~h}$ post-inoculation and analyzed using the GeXP system. As shown in Fig. S9A-C, the expression of all protein foldingassociated genes in strain S8-H was higher than that in strain $\mathrm{S} 8$ at each time point, but was particularly noticeable at $48 \mathrm{~h}$ post-inoculation. The greatest differences in expression between the two strains were observed for HAC1, SEC53, and PDI1.

Although strain S8 showed the highest level of xylanase expression among the high copy number strains, the overexpression of HAC1 significantly increased the expression of CPR5, CEN1, ER01, KAR2, PDI1, and SEC53 compared with the expression levels in strain S8. It is possible that the overexpression of HAC1 increased the involvement of the proteins encoded by the tested genes in the process of protein folding and assembly, ensuring proper folding and assembly of protein in the ER. In addition, the expression of $\mathrm{xynB}$ in strain $\mathrm{S} 8-\mathrm{H}$ was higher than that in strain $\mathrm{SO}$ at all time points, which provides evidence that the overexpression of HAC1 could further improve the expression of xynB.

\subsubsection{Qualitative and quantitative analysis of protein folding-associated genes in strains $\mathrm{SO}-\mathrm{H}, \mathrm{S} 1-\mathrm{H}, \mathrm{S} 8-\mathrm{H}$, and $\mathrm{S} 22-\mathrm{H}$}

The sequential changes in expression of genes associated with ER protein folding following overexpression of HAC1 in S. cerevisiae strain S0 are shown in Fig. S10. The GeXP quantitative analysis tool was then used to quantitatively analyze the expression levels of each of the genes at different time points (Fig. 5A). Strain SO did not express xylanase protein, but the overexpression of HAC1 still triggered changes in a series of genes associated with protein folding, which indirectly indicated that HAC1 could regulate the expression of these genes. As shown in Fig. S10 and Fig. 5A, the expression of genes associated with protein folding involved a series of sequential changes; specifically, the expression of each gene increased over time. Among the tested genes, the greatest increases in expression were 
observed for protein disulfide isomerase-encoding gene PDI1 and phosphomannose-encoding gene SEC53. Compared with the levels at $24 \mathrm{~h}$ post-inoculation, the expression levels of PDI1 and SEC53 at $48 \mathrm{~h}$ and $72 \mathrm{~h}$ post-inoculation were increased by 5.51-fold and 8.54-fold and 4.04-fold and 3.19-fold, respectively. In comparison, the expression of $\mathrm{HAC} 1$ at $72 \mathrm{~h}$ post-inoculation decreased by $36.3 \%$ compared with that at $48 \mathrm{~h}$, suggesting higher levels of protein synthesis at $48 \mathrm{~h}$ post-inoculation than at $72 \mathrm{~h}$, and that HAC1 may only be partially expressed at the later time point.

The results of GeXP analysis of gene expression in single-copy xynB strain S1-H are shown in Fig. S11 and Fig. 5B. Compared with strain $\mathrm{S} 0-\mathrm{H}$, the expression levels of all protein folding-associated genes were significantly increased, suggesting that they all participated in the expression of xylanase. At $72 \mathrm{~h}$ postinoculation, the expression of cyclophilin protein-encoding gene CPR5, protein disulfide isomeraseencoding gene ERO1, and calcium binding protein-encoding gene CNE1 was decreased compared with that at $48 \mathrm{~h}$. It is possible that the single-copy expression of xylanase did not cause stress on the ER, and that the basal level of expression of the protein folding-associated genes was sufficient to cover the needs of protein folding and assembly. In addition, the expression of xynB reached a maximum at $72 \mathrm{~h}$ post-inoculation, which was consistent with the enzyme activity results showing that enzyme activity reached a maximum at $72 \mathrm{~h}$.

Strain S8 had the highest level of xylanase expression. However, overexpression of HAC1 further improved the expression levels. We speculated that overexpression of HAC1 may enhance the capacity of the cells to process heterologous proteins. We then investigated gene expression in strain S8-H at $24 \mathrm{~h}$, $48 \mathrm{~h}$, and $72 \mathrm{~h}$ post-inoculation using the GeXP system (Fig. S11 and Fig. 5C). Results showed that overexpression of HAC1 resulted in increased expression of all protein folding-associated genes except CPR5, the protein product of which participates in post-translational modification of proteins, and CEN1, whose corresponding protein is involved in glycosylation modification of proteins. At $72 \mathrm{~h}$ postinoculation, the expression of CPR5 and CEN1 was decreased, which may be associated with the hysteresis effect of protein synthesis and secretion, or with the activation of the UPR by HAC1 gene expression, which triggers protein degradation and a series of changes within the cell. These results suggested that the expression and secretion of proteins is a complicated process. At $72 \mathrm{~h}$ postinoculation, the expression of HAC1 was 4.09-fold and 2.03-fold higher than that at $24 \mathrm{~h}$ and $48 \mathrm{~h}$, respectively. Accordingly, it might be possible that in addition to the activated HAC1 gene, the endogenous S. cerevisiae HAC1 gene was also expressed. In addition, further investigation showed that xynB expression at the three different time points showed similar patterns of enzyme production, reaching 154,265 at $72 \mathrm{~h}$ post-inoculation, which was the highest protein yield among all strains. This finding confirmed that eight copies of xynB resulted in the highest xylanase productivity.

Strain S22 had the highest xynB copy number but this did not correlate with the highest levels of xylanase expression. Gene expression levels in strain $\mathrm{S} 8-\mathrm{H}$ at $24 \mathrm{~h}, 48 \mathrm{~h}$, and $72 \mathrm{~h}$ post-inoculation were investigated using the GeXP system, and results are shown in Fig. S11 and Fig. 5D. The expression levels of protein folding-associated genes were significantly increased at $48 \mathrm{~h}$ and $72 \mathrm{~h}$ post-inoculation compared with levels in strain S22. However, at $24 \mathrm{~h}$ post-inoculation, gene expression levels of strain 
S22-H were lower than those of strain S1-H. The high gene copy number in strain S22-H could lead to high levels of the xylanase protein, causing cellular stress and resulting in retarded growth in the early stages of cultivation. Moreover, compared with the 24-h and 48-h time points, gene expression levels in strain S22-H were increased at $72 \mathrm{~h}$ post-inoculation. This suggested that at $72 \mathrm{~h}$ post-inoculation, the synthesis of heterologous proteins required the participation of protein folding and assembly genes, which was consistent with the results of xylanase gene and enzyme production analyses for this strain.

\section{Discussion}

\subsection{Constitutive secretory expression of xylanase via the PGK promoter and a-factor signal peptide}

The promoter is one of the most crucial elements of an expression vector because it influences the mRNA synthesis rate. Accordingly, a strong promoter contributes to higher expression of a heterologous protein $^{[19]}$. To improve the expression of cellobiohydrolase in A. niger, Qin et al. used the glaA promoter sequence, which promotes the expression of glucoamylase, to drive the expression of the $\mathrm{CBH}$ gene. Enzyme activity testing showed that the filter paper activity of the resulting recombinant strains was 2.51fold higher than that of the wild-type A. niger strain ${ }^{[23]}$. In the current study, the galactose-inducible promoter in the vector was replaced with the constitutive promoter PGK, allowing direct expression of xylanase in YPD medium and significantly improving expression in the recombinant strains.

Signal peptides are short peptides that guide the secretion of newly-synthesized heterologous proteins and improve their solubility, making them the focus of many studies in recent years ${ }^{[24,25]}$. The amyE signal peptide-encoding region from the genome of Bacillus subtilis BS168 was used to guide the secretory expression of multifunctional amylases OPMA-N and OPMA-G by Li et al. ${ }^{[26]}$ Sodium dodecyl sulfate polyacrylamide gel electrophoresis analysis showed that the introduction of the signal peptide improved the secretion of the heterologous proteins. In the current study, the preferred S. cerevisiae signal peptide, from a-factor, was used to construct a strain in which xylanase was successfully excreted.

\subsection{Improvement of xylanase expression by the introduction of multiple gene copies}

Gene copy number limits the expression levels of heterologous protein. Accordingly, increasing the number of copies of a target gene can effectively increase the heterologous protein yield. Jeong et al. showed that an increased gene copy number improved the production of tripeptide His-His-Leu compared with the single gene copy strain, and found that the protein was more stable ${ }^{[27]}$. Tamakawa et al. developed a series of strains containing 1-10 copies of genes $m X Y L 1, X Y L 2$, and XYL3, encoding mutated xylose reductase K275R/N277D, C-xylitol dehydrogenase, and xylulokinase, respectively, to examine the relationship between gene expression and copy number. Their results showed that there was a positive but non-multiple relationship between the two variables ${ }^{[28]}$. Another study showed that for secreted proteins, copy number and protein expression levels were positively correlated within a certain 
range, with 4-9 gene copies being optimal and additional copies resulting in decreased protein expression ${ }^{[29]}$. In the current study, we examined the xylanase activity of transformants containing different copy numbers of xynB. The results showed that eight gene copies resulted in maximum xylanase activity, but that when the copy number exceeded eight, xylanase activity decreased. These results confirmed that increasing the gene copy number does not necessarily increase protein expression.

\subsection{Overexpression of HAC1 enhances the expression of heterologous proteins}

HAC1, the transcriptional regulator of the UPR pathway, interacts with a large number of molecular chaperones associated with protein folding and assembly. The UPR mechanism in eukaryotic expression systems has been a hot topic in recent years, and much research focused on improving the expression levels of heterologous proteins by regulating $\mathrm{HAC} 1$ expression and the expression of genes associated with protein folding in the ER has been conducted ${ }^{[30,31]}$. Tae-Hee Lee et al. studied the effects of overexpression of a UPR pathway gene in recombinant S. cerevisiae strains harboring 16 copies of the gene coding for human kringle protein LK8. HAC1p promotes LK8 protein production as well as cell

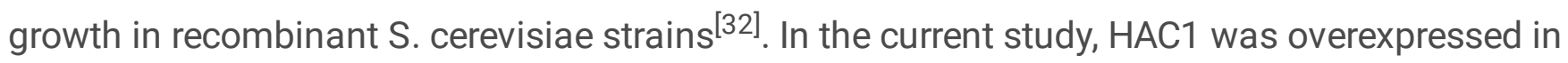
recombinant $S$. cerevisiae strains containing one, eight (the highest enzyme activity), or 22 (the highest number of copies) copies of xynB, with overexpression of HAC1 in the wild-type strain used as a control. The expression levels of protein folding-associated genes with and without HAC1 overexpression were then investigated using the GeXP system. The results showed that even in the wild-type (SO) strain, overexpression of $\mathrm{HAC} 1$ enhanced the expression of protein folding-associated genes. In addition, compared with strains S8 and S22, the gene expression levels in strains S8-H and S22-H were significantly increased, indicating that eight and 22 copies of xynB caused stress in the ER .

In S. cerevisiae expression systems, the production and accumulation of misfolded proteins, especially the overexpression of proteins from multiple copies of a gene, are key to the efficient expression of heterologous proteins ${ }^{[33]}$. These proteins cannot be properly folded, so they will be accumulated in the ER, triggering the ER-associated protein degradation (ERAD) pathway, resulting in degradation by ER protease. By investigating the expression levels of genes associated with protein folding in strains $\mathrm{S} 8 \mathrm{-H}$ and S22-H, we determined that in high-copy strains, the sequential changes in gene expression levels were not as regular as those in low-copy and wild-type strains. We predict that this may be caused by the effects of the ERAD pathway on gene expression.

\section{Conclusions}

By applying rDNA integration, multi-copy constitutive secretory expression of xylanase was successfully achieved in S. cerevisiae. Strain S8, with eight copies of xynB, showed the highest levels of xylanase expression, reaching a final yield of $325 \mathrm{U} / \mathrm{mL}$. However, overexpression of HAC1 increased the xylanase production capacity of strain S8, resulting in a final yield of $381 \mathrm{U} / \mathrm{mL}$. Overall, this study revealed that overexpression of HAC1 enhances the expression of genes associated with protein folding in the ER and 
improves the function of the ER with regard to protein folding, which in turn further enhances the expression of xylanase.

\section{Declarations}

\section{Ethics approval and consent to participate}

The experimental protocol was established, according to the ethical guidelines of the Helsinki Declaration and was approved by the Human Ethics Committee of Jilin Agricultural University. Written informed consent was obtained from individual or guardian participants.

\section{Consent for publication}

Not applicable.

\section{Availability of data and material}

All data generated or analysed during this study are included in this published article.

\section{Competing interests}

The authors declare that they have no competing interests.

\section{Funding}

This study was funded by the National Key R\&D Program of China (2017YFD0501005).

\section{Acknowledgments}

We thank the National Key R\&D Program of China, the Key Laboratory of Straw Biology and Utilization, The Ministry of Education, for its support. We also thank Tamsin Sheen, PhD, from Liwen Bianji, Edanz Editing China (www.liwenbianji.cn/ac), for editing the English text of a draft of this manuscript.

\section{Authors' contributions}

Sitong Zhang designed the experimental scheme and wrote the article. Changjie Bao undertook the carrier construction experiment and data processing. Jiping Li analyzed the experimental data. Huan Chen and Yang Sun undertook the bacteria performance analysis experiment. Wang Gang and Guang Chen revised the experimental scheme and manuscript. All authors read and approved the final manuscript.

\section{References}

[1] Dos S T, Masey O H, Gonzalez-Ortiz G, et al. Xylanase, protease and superdosing phytase interactions in broiler performance, carcass yield and digesta transit time[J]. Anim Nutr, 2017,3(2):121126. 
[2] Gomez S, Payne A M, Savko M, et al. Structural and functional characterization of a highly stable endo-beta-1,4-xylanase from Fusarium oxysporum and its development as an efficient immobilized biocatalyst[J]. Biotechnol Biofuels, 2016,9(1):191.

[3] Sharma R, Katoch M, Govindappa N, et al. Evaluation of the catalase promoter for expressing the alkaline xylanase gene (alx) in Aspergillus niger[J]. FEMS Microbiol Lett, 2012,327(1):33-40.

[4] Levisson M, Patinios C, Hein S, et al. Engineering de novo anthocyanin production in Saccharomyces cerevisiae[J]. Microb Cell Fact, 2018,17(1):103.

[5] Katsuki Y, Yamaguchi Y, Tani M. Overexpression of PDR16 confers resistance to complex sphingolipid biosynthesis inhibitor aureobasidin A in yeast Saccharomyces cerevisiae[J]. FEMS Microbiol Lett, 2018,365(3).

[6] Michel C J, Ngoune V N, Poch O, et al. Enrichment of Circular Code Motifs in the Genes of the Yeast Saccharomyces cerevisiae[J]. Life (Basel), 2017,7(4).

[7] Oguro $\mathrm{Y}$, Yamazaki $\mathrm{H}$, Shida $\mathrm{Y}$, et al. Multicopy integration and expression of heterologous genes in the oleaginous yeast, Lipomyces starkeyi[J]. Biosci Biotechnol Biochem, 2015,79(3):512-515.

[8] Wu Y, Gao T, Wang X, et al. TALE nickase mediates high efficient targeted transgene integration at the human multi-copy ribosomal DNA locus[J]. Biochem Biophys Res Commun, 2014,446(1):261-266.

[9] Lin Y F, Haynes C M. Metabolism and the UPR(mt)[J]. Mol Cell, 2016,61(5):677-682.

[10] Senft D, Ronai Z A. UPR, autophagy, and mitochondria crosstalk underlies the ER stress response[J]. Trends Biochem Sci, 2015,40(3):141-148.

[11] Decraene C, Silveira A B, Bidard F C, et al. Multiple Hotspot Mutations Scanning by Single Droplet Digital PCR[J]. Clin Chem, 2018,64(2):317-328.

[12] Weerakoon K G, Gordon C A, Williams G M, et al. Droplet Digital PCR Diagnosis of Human Schistosomiasis: Parasite Cell-Free DNA Detection in Diverse Clinical Samples[J]. J Infect Dis, 2017,216(12):1611-1622.

[13] Kutyrev I, Cleveland B, Leeds T, et al. Dataset of proinflammatory cytokine and cytokine receptor gene expression in rainbow trout (Oncorhynchus mykiss) measured using a novel GeXP multiplex, RT-PCR assay[J]. Data Brief, 2017,11:192-196.

[14] LAN Xue, ZHANG Sitong, LI Zhe, et al. Application of droplet digital PCR in screening of genetically modified Saccharomyces cerevisiae for multicopy expression of xylanase[J]. Food Science, 2018, 39(10): 179-184. (in Chinese with English abstract) DOI:10.7506/spkx1002-6630-201810028. 
[15] Kim H, Lee H S, Park H, et al. Enhanced production of xylitol from xylose by expression of Bacillus subtilis arabinose: $\mathrm{H}(+)$ symporter and Scheffersomyces stipitis xylose reductase in recombinant Saccharomyces cerevisiae[J]. Enzyme Microb Technol, 2017,107:7-14.

[16] Yamada R, Wakita K, Mitsui R, et al. Enhanced d-lactic acid production by recombinant Saccharomyces cerevisiae following optimization of the global metabolic pathway[J]. Biotechnol Bioeng, 2017,114(9):2075-2084.

[17] Gibellini L, Pecorini S, De Biasi S, et al. Exploring viral reservoir: The combining approach of cell sorting and droplet digital PCR[J]. Methods, 2018,134-135:98-105.

[18] Saputra F, Shiu Y L, Chen Y C, et al. Dietary supplementation with xylanase-expressing B. amyloliquefaciens R8 improves growth performance and enhances immunity against Aeromonas hydrophila in Nile tilapia (Oreochromis niloticus)[J]. Fish Shellfish Immunol, 2016,58:397-405.

[19] Casa-Villegas M, Marin-Navarro J, Polaina J. Synthesis of Isomaltooligosaccharides by Saccharomyces cerevisiae Cells Expressing Aspergillus niger alpha-Glucosidase[J]. ACS Omega, 2017,2(11):8062-8068.

[20] Mori T, Ogasawara C, Inada T, et al. Dual functions of yeast tRNA ligase in the unfolded protein response: unconventional cytoplasmic splicing of HAC1 pre-mRNA is not sufficient to release translational attenuation[J]. Mol Biol Cell, 2010,21(21):3722-3734.

[21] Bunt J, Hasselt N E, Zwijnenburg D A, et al. Joint binding of OTX2 and MYC in promotor regions is associated with high gene expression in medulloblastoma[J]. PLoS One, 2011,6(10):e26058.

[22] Sainz J, Segura-Catena J, Jurado M. [Association between genetic polymorphism in the promotor region of CD209 and propensity to develop invasive pulmonary aspergillosis][J]. Methods Find Exp Clin Pharmacol, 2010,32 Suppl A:9-13.

[23] Qin H B, Yang H J, Huang W, etc. Expression of cbhB Gene Driven by Promoter glaA in Aspergillus Niger, China Biotechnology, 2010, 30(11): 34-38.

[24] Dirican N, Duman A, Saglam G, et al. The diagnostic significance of signal peptide-complement $\mathrm{C} 1 \mathrm{r} / \mathrm{C} 1 \mathrm{~s}$, Uegf, and Bmp1-epidermal growth factor domain-containing protein-1 levels in pulmonary embolism[J]. Ann Thorac Med, 2016,11(4):277-282.

[25] Mordkovich N N, Okorokova N A, Veiko V P. [Structural and Functional Organization of the Signal Peptide of ProEnterotoxin B from Staphylococcus aureus][J]. Prikl Biokhim Mikrobiol, 2015,51(6):561569.

[26] Li Y F, Zhang J X, Gu Y Q, Effects of Signal Peptide on the Secretory Expression of Multifunctional Amylase OPMA and Its Catalytic Activity, Chemical Journal of Chinese Universities, 2013, 34(10), 23342339. 
[27] Jeong D W, Shin D S, Ahn C W, et al. Expression of antihypertensive peptide, His-His-Leu, as tandem repeats in Escherichia coli[J]. J Microbiol Biotechnol, 2007,17(6):952-959.

[28] Tamakawa H, Ikushima S, Yoshida S. Construction of a Candida utilis strain with ratio-optimized expression of xylose-metabolizing enzyme genes by cocktail multicopy integration method[J]. J Biosci Bioeng, 2013,115(5):532-539.

[29] Lin X Q, Liang S L, Han S Y, et al. Quantitative iTRAQ LC-MS/MS proteomics reveals the cellular response to heterologous protein overexpression and the regulation of HAC1 in Pichia pastoris[J]. J Proteomics, 2013,91:58-72.

[30] Zhang L, Zhang C, Wang A. Divergence and Conservation of the Major UPR Branch IRE1-bZIP Signaling Pathway across Eukaryotes[J]. Sci Rep, 2016,6:27362.

[31] Feng X, Krishnan K, Richie D L, et al. HacA-independent functions of the ER stress sensor IreA synergize with the canonical UPR to influence virulence traits in Aspergillus fumigatus[J]. PLoS Pathog, 2011,7(10):e1002330.

[32] Lee T, Bae Y, Kim M, et al. Overexpression of HAC1 gene increased levels of both intracellular and secreted human kringle fragment in Saccharomyces cerevisiae[J]. Process Biochemistry, 2012,47(12):2300-2305.

[33] Cakir B. Bax induces activation of the unfolded protein response by inducing HAC1 mRNA splicing in Saccharomyces cerevisiae[J]. Yeast, 2012,29(9):395-406.

\section{Figures}

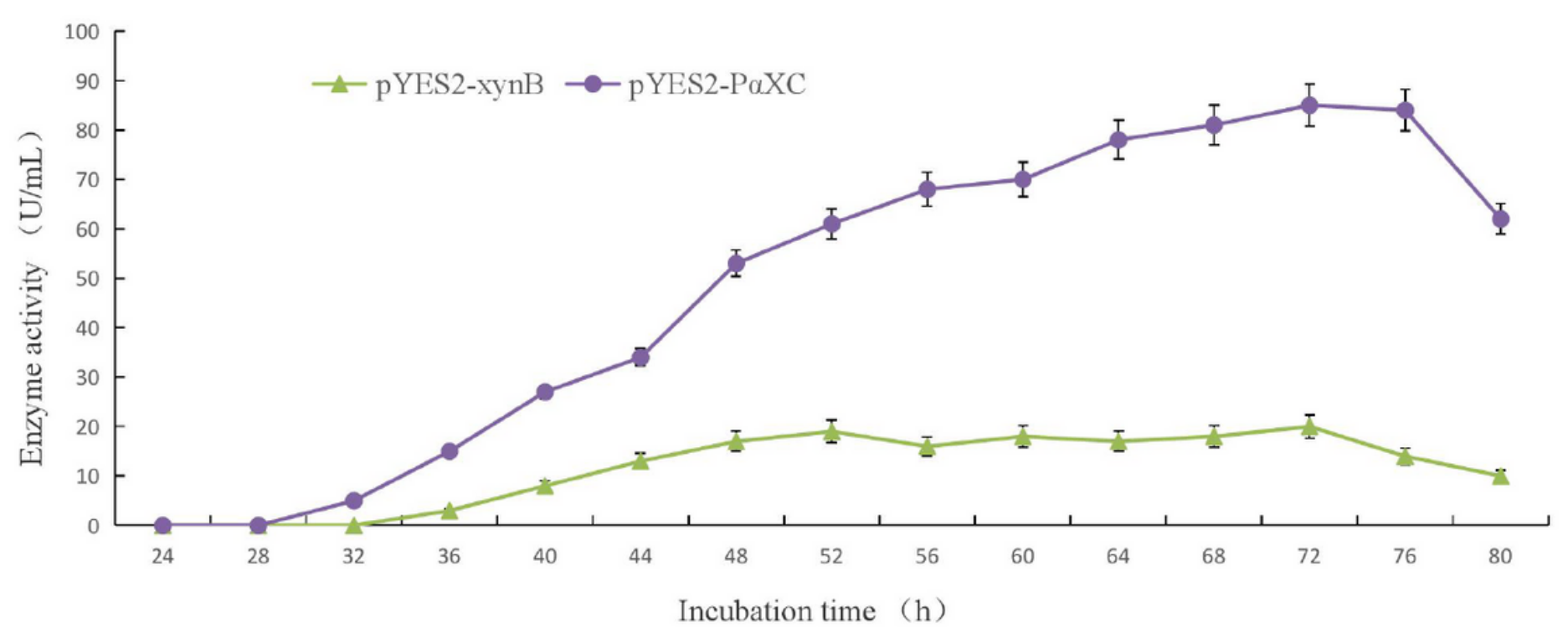

Figure 1 
Xylanase activity of S. cerevisiae strains INVSc1-pYES2-xynB and INVSc1-pYES2-PaXC. The effects of the PGK promoter and the a-factor signal peptide on xylanase production were examined by measuring the xylanase activity of the culture supernatants of the two strains.

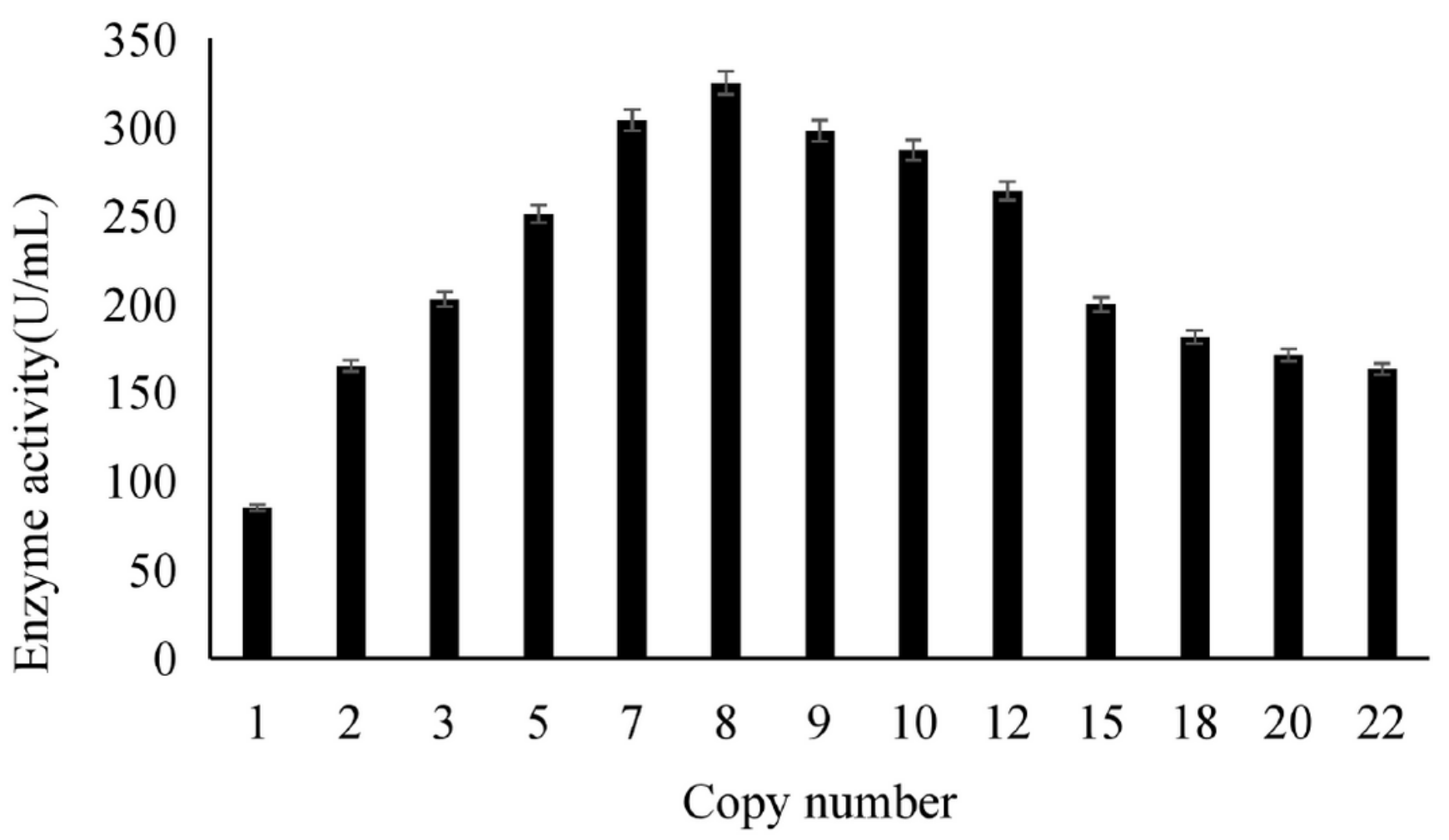

Figure 2

Relationship between xynB copy number and enzyme activity 


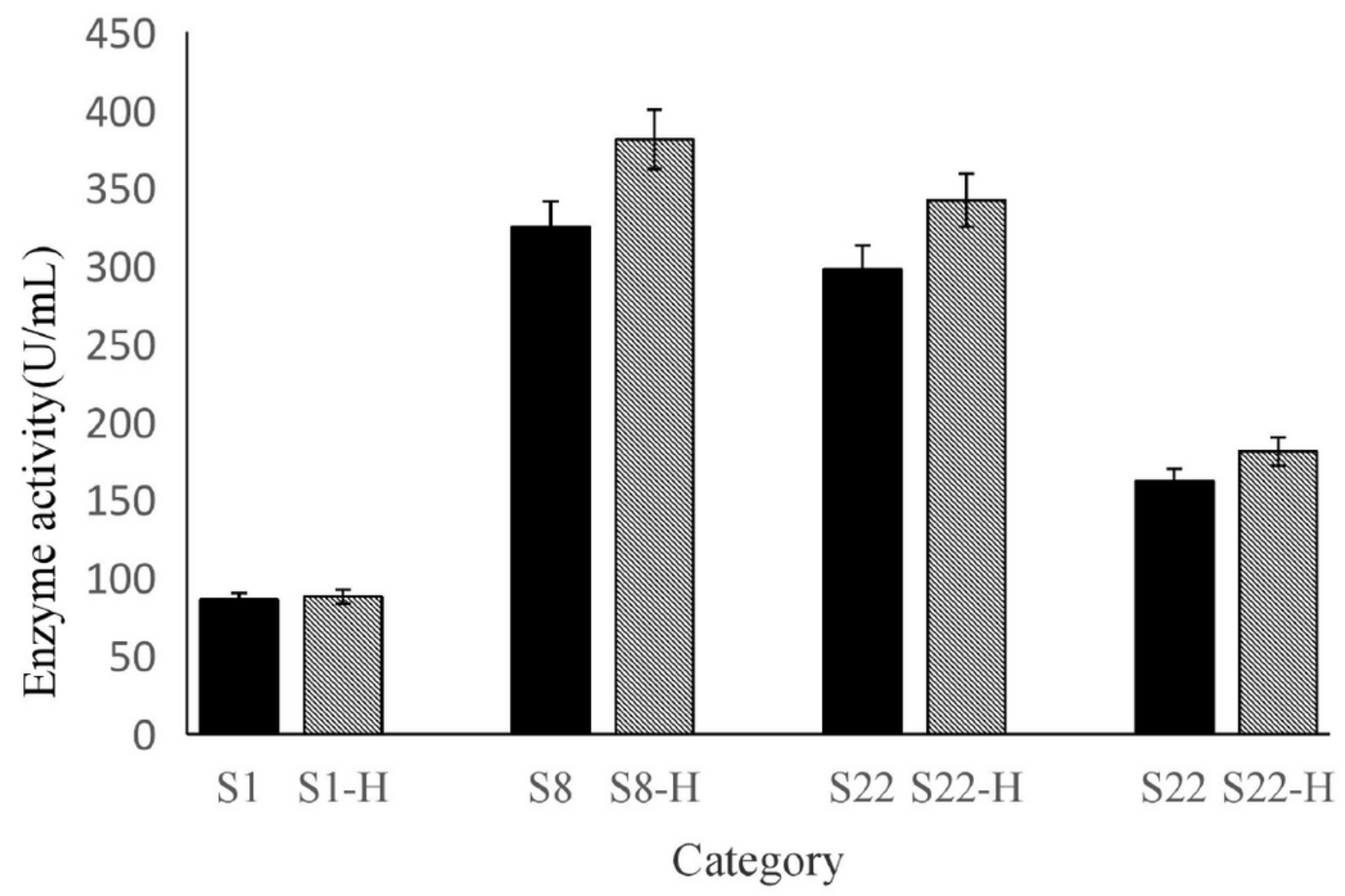

Figure 3

Effects of overexpression of HAC1 on xylanase enzyme activity

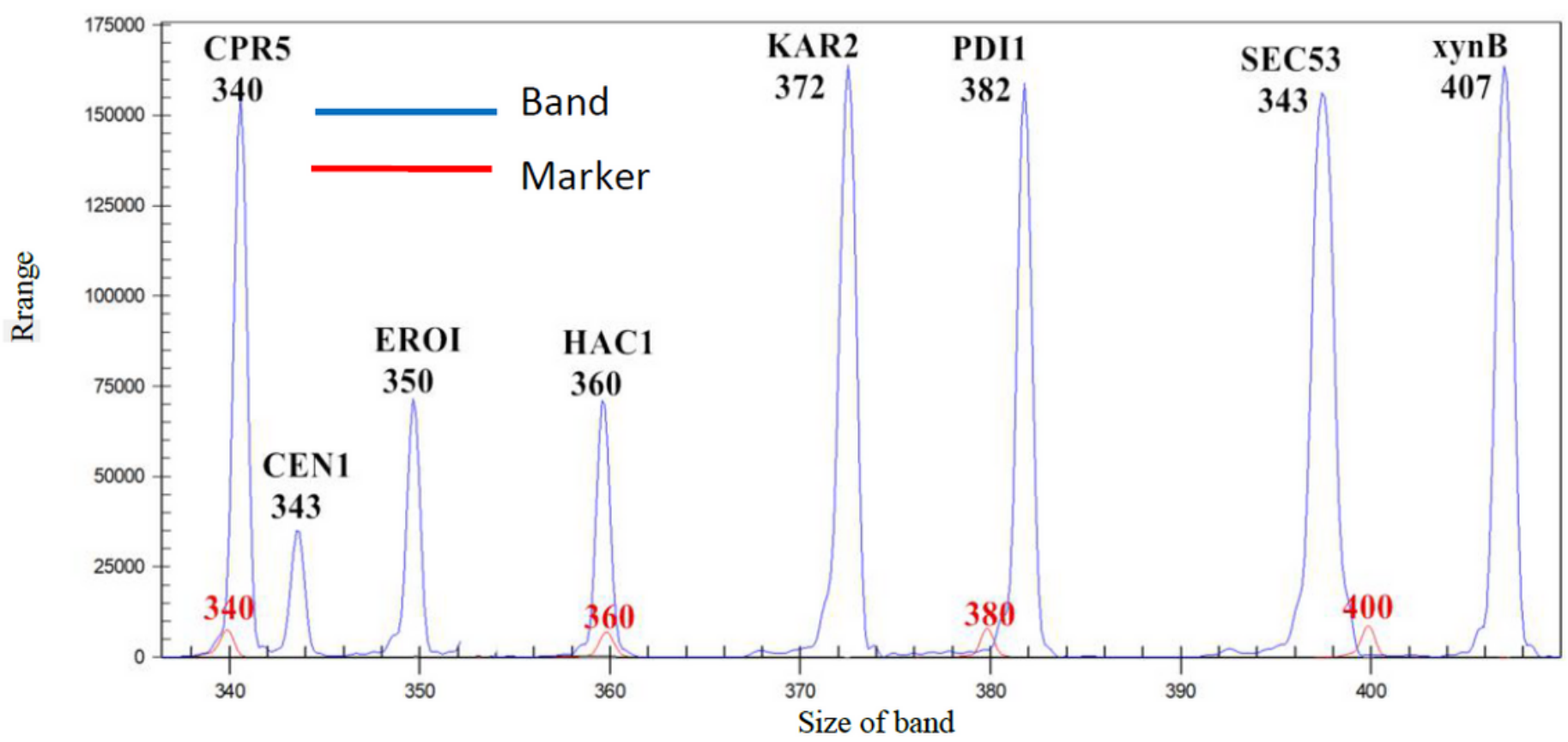


Figure 4

Electrophoresis of reactions containing mixed primers
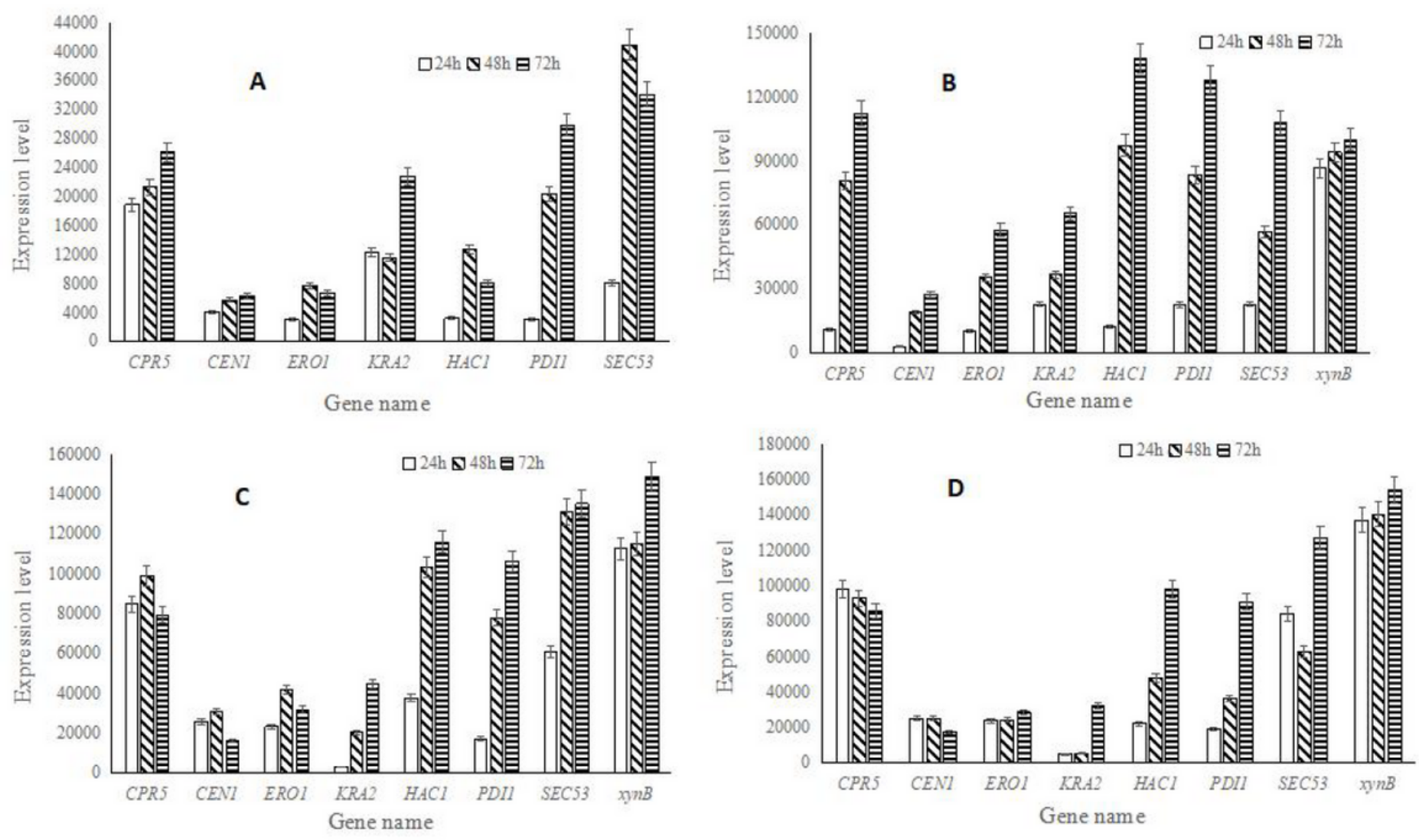

Figure 5

Quantitative analysis of protein folding-associated genes in strains S0-H (A), S1-H (B), S8-H (C), and S22$H(D)$.

\section{Supplementary Files}

This is a list of supplementary files associated with this preprint. Click to download.

- Abbreviations.pdf

- Highlights.pdf

- SupportInformation.pdf 